\title{
A PÓS-MODERNIDADE E O PENSAMENTO SOCIAL: COMPLEMENTARIEDADE OU ANTAGONISMO?
}

\author{
Leonardo Luiz Silveira da Silva \\ Instituto Federal do Norte de Minas Gerais (IFNMG), Campus Salinas, Minas Gerais, Brasil \\ leoluizbh@hotmail.com
}

\begin{abstract}
RESUMO
É bastante difundido que os pressupostos da pós-modernidade criam dificuldades para o pensamento e, consequentemente, ação social. Esta ideia se sustenta a partir do entendimento que a pós-modernidade contribui para a desconstrução da materialidade de conceitos-chave que servem às reivindicações sociais, além de promover o questionamento das metanarrativas e dos discursos da modernidade. Após perpassar por uma discussão sobre a materialidade e a imaterialidade, o artigo reflete sobre o e m bate entre a pós-modernidade e o pensamento social, chegando à conclusão de que em certas perspectivas se configura o antagonismo e, em outras, a complementariedade, sendo esta discussão necessária para que a geografia mantenha o protagonismo no debate interdisciplinar.
\end{abstract}

Palavras-Chave: Pós-Modernidade. Geografia. Pensamento Social.

\section{POSTMODERNITY AND SOCIAL THOUGHT: COMPLEMENTARITY OR ANTAGONISM?}

\begin{abstract}
It is widespread that the assumptions of postmodernity create difficulties for thought and, consequently, social action. This idea is based on the understanding that postmodernity contributes to the deconstruction of the materiality of key concepts that serve social demands, in addition to promoting the questioning of meta-narratives and discourses of modernity. After going through a discussion about materiality and immateriality, the article reflects on the clash between postmodernity and social thought, coming to the conclusion that in certain perspectives antagonism and, in others, complementarity, being this discussion necessary if geography aims to maintain protagonism in the interdisciplinary debate.
\end{abstract}

Keywords: Post-Modernity. Geography. Social Thinking.

\section{INTRODUÇÃO}

O artigo de Fred K. Schaefer (1953) posiciona-se de forma icônica, inter alia, por ser considerado um trabalho seminal do neopositivismo na geografia (HARVEY, 1969; HARTSHORNE, 1978; SACK, 1972 e 1974; SMITH, 1979; JOHNSTON, 1986; CAPEL, 2013). A virada cultural - movimento interdisciplinar que ocorreu na passagem dos anos 1960 e 1970 - estabeleceu-se como um contexto intelectual de questionamento da perspectiva neopositivista (MIKESELL, 1978; VALENTINE, 2001; PEDROSA, 2016) com impactos notáveis para a geografia (CORRÊA; ROSENDAHL, 2011). Aprioristicamente, as críticas foram encampadas a partir de uma perspectiva idealista (GUELKE, 2003) pela geografia humanista (LEY, 1981; POCOCK, 1983; GOLD; GOODEY, 1983; LEITE, 1998, CABRAL, 2000), corrente amplamente marcada pela intersubjetividade das interpretações ligadas ao lugar e à paisagem. Em um outro espectro analítico, mas também portador de críticas substanciais ao neopositivismo, desenvolveu-se a geografia crítica, insatisfeita com a neutralidade objetivada pela geografia quantitativa. A geografia crítica carrega o entendimento que a geo grafia serve como um instrumento político (LACOSTE, 2005).

Nota-se, sobremaneira, uma polarização entre o idealismo e o materialismo no âmbito reativo ao neopositivismo. Como as correntes de pensamento são rótulos dotados de escopos não tão bem delineados, pudemos assistir o confronto entre idealismo e materialismo na dimensão das próprias correntes, como na nova geografia cultural, que floresceu nos anos 1980 (GREGSON, 1992; SCOTT, 2004; CRESSWELL, 2010). Esta situação ficou bastante evidenciada a partir da publicação de um artigo por parte de Don Mitchell (1995) que instigou outros autores ao debate. Intitulado There's no such thing as culture, Mitchell desdenhou das abordagens ontológicas da cultura, citando alguns

$\begin{array}{lllll}\text { Caminhos de Geografia } & \text { Uberlândia-MG } & \text { v. 22, n. } 82 & \text { ago./2021 } & \text { p.41-52 }\end{array}$


baluartes dos estudos culturais da geografia como intelectuais que se apropriaram de uma forma materialista que reificou o conceito de cultura. Este artigo estimulou réplicas e uma tréplica (DUNCAN; DUNCAN, 1996; COSGROVE, 1996; JACKSON, 1996, MITCHELL, 1996).

A discussão que envolve a oposição entre o materialismo e o idealismo ainda levou alguns autores a criticarem a divisão entre matérias e ideias, como Tim Ingold (1993) e Augustin Berque (2012 e 2017). A base desta crítica refere-se ao entendimento de uma construção dialética entre mente e matéria, que se expressaria nestes termos: o ambiente interfere na forma de pensar do homem, da mesma forma que a agência humana impacta sobre o ambiente (BERQUE, 2017).

Neste ambiente marcado por uma pletora de ideias, ganha força a corrente pós-modernista de pensamento, ainda que tardiamente na geografia (OAKES, 1997; MINCA, 2009). Chegando como um intruso na geografia, seus pressupostos causaram desconforto nas demais correntes geográficas, notavelmente na geografia crítica, num fenômeno muito similar ao ocorrido nas teorias sociais de outras disciplinas das humanidades. É largamente dif undido que os pressupostos pós-modernos criam dificuldade para os movimentos sociais. Até que ponto concordamos com esta assertiva? É o objetivo deste artigo problematizar as relações envolvendo os pressupostos pós-modernista e a crítica social. Esta é a razão para lançarmos a questão no título deste trabalho: A pós-modernidade e - social estabelecem uma relação de complementariedade ou antagonismo? Para tanto, problematizaremos inicialmente as relações envolvendo a materialidade e a imaterialidade e seu impacto para a interpretação geográfica. Posteriormente abordaremos a pós-modernidade e o impacto dos seus pressupostos sobre o pensamento social.

É importante destacar que as correntes de pensamento geográfico se apresentam como rótulos. Acreditamos nas estruturas híbridas de pensamento, que, ao contrário das rotulações, transitam por diferentes mainstreams geográficos. Deste modo, os autores, em sua individualidade, dificilm ente se enquadram na quintessência quase normativa das correntes geográficas, apres entando-se como mentes livres capazes de transitar pelos distintos escopos ideológicos. Por outro lado, as rotulaçõ es possuem força discursiva, justamente por simplificar o que é complexo. Esperamos com isso termos alertado que a utilização da palavra "pós-modernidade", "pós-moderno" ou ainda "pós-modernismo", referem-se neste artigo aos pressupostos que comumente são associados à descrição deste rótulo.

\section{MATERIALIDADE E IMATERIALIDADE}

A discussão entre a materialidade e a imaterialidade é de suma importância para avaliarmos, a posteriori, os ef eitos dos pressupostos do pós-modernismo sobre o pensamento social. De partida, consideramos que a paisagem e a cultura carregam em si uma oposição constante entre "materialidade" e "imaterialidade" (NAME, 2010). Diferentes indivíduos podem ter distintos entendimentos sobre os significados dos elementos materiais. Portanto, há a possibilidade de materializações apresentarem-se intersubjetivamente, assim como imaterialidades podem encontrar espantoso consenso (ainda que não seja absoluto) entre indivíduos.

Preocupado quanto à questão dos significados dos objetos, Berque (2012) cria uma oposição entre topos e chôra, conceitos que opõem, respectivamente, a dimensão meramente descritiva dos objetos e a descrição holística, que vai muito além de sua manifestação material. Berque afirma que "a realidade vai além do material, ao mesmo tempo retornando a ele também" (BERQUE, 2012, p.7). É curioso pensarmos também que as ideias humanas moldam a paisagem, ao mesmo tempo em que a experiência humana molda as ideias (WALTON, 1995). Para contemplar esta dimensão holística dos objetos materiais, Augustin Berque sugeriu a palavra geograma ao anunciar que "imaginar a Terra sem o céu, ou o inverso, não passa de uma abstração" (BERQUE, 2012, p.8). Como dito, enquanto geogramas que superam a dimensão da descrição física, os objetos não podem ser meramente descritos. O trecho a seguir explora o simbolismo que está por detrás dos corpos físicos:

A espécie humana se tornou o que é devido a um processo imensamente longo durante o qual o fisiológico, o técnico e o simbólico não cessaram de interagir. Pelo que nos diz respeito, esta interação se traduziu por uma "exteriorização" progressiva das funções do corpo humano, que começou quando os nossos ancestrais, por assim dizer, extraíram seus incisivos de suas bocas para colocá-los na mão, na forma de pedras lascadas. Momento bem considerável e da maior eficácia! Este vantajoso processo nunca parou de se ampliar, constituindo, assim, pouco a pou co, nosso "corpo social" que é exterior ao nosso "corpo animal", que só faz esten der as funções naturais que fazem parte, com todas as coisas que as compõem, de nossa corporeidade global (BERQUE, 2012, p.9). 
A reflexão de Berque se associa diretamente no processo descritivo da paisagem e do lugar. Os objetos que compõem estas duas categorias geográficas vão além do seu corpo físico, constituindo se como geogramas. A reflexão assemelha-se ao argumento de Cosgrove (1983) acerca da atividade humana. Para o autor, toda atividade humana é, ao mesmo tempo, material e simbólica, produção e comunicação. Na verdade, na dimensão de Augustin Berque (2017), a objetividade e a subjetividade são extensões de um mesmo fenômeno, sendo sua dicotomia, stricto sensu, falaciosa. De certa forma os geogramas apresentam-se periféricos ao seu pensamento, que tem no conceito de trajeção o seu microcosmo.

A trajeção, por sua vez, é o processo evolutivo no qual o ambiente é antropizado pela técnica e humanizado pelo símbolo, o que faz um meio humano e onde, simultaneamente, em retorno, este meio condiciona o humano para, indefinidamente, humaniza-lo de volta e assim por diante (BERQUE, 2017, p.6).

Assim Berque define que o ambiente e o homem estão em constante interação material e imaterial, de tal maneira que se torna desafiante separar estas duas dimensões interativas. Desta forma, contestando a dicotomia entre a objetividade e a subjetividade que guiam a interpretação da paisagem, o autor define que "em suma, a realidade do meio não é propriamente objetiva (porque ela pressupõe uma interpretação), nem propriamente subjetiva (porque ela pressupõe o ambiente). Ela é trajetiva" (BERQUE, 2017, p.7).

Augustin Berque conseguiu sintetizar e dar nome aos processos nos quais a materialidade e a imaterialidade dialogam e se fomentam. Seus méritos concentram-se na capacidade de explicação acerca da complexa interação entre homem e ambiente. Na concepção de Berque, não há uma zona de contato entre as elaborações objetivas e subjetivas. A trajeção representa uma franca relação retroalimentada e permanente de constituição daquilo que Sauer (2008) chamou de "fatos geográficos". É como se a trajeção fosse o fenômeno em si, e não um processo que une fenômenos. A trajeção é a totalidade da relação homem ambiente, que não pode ser dimensionada em toda sua constituição, tamanha é a infinidade de pensamentos e ações que direta ou indiretamente contribuem para modelar a dimensão do visível. Em 1978, Denis Cosgrove já abordava esta dialética que envolve o homem, o ambiente, a materialidade e a imaterialidade, ao dizer que "as ideias humanas moldam a paisagem, as intenções humanas criam e mantém lugares, mas a nossa experiência no espaço e no lugar propriamente molda as ideias humanas" (COSGROVE, 1978, p.66), e ainda salienta: "a racionalidade dialética requer que a mente e a matéria seja vista em interação uma com a outra" (COSGROVE, 1978, p.70). Há de se considerar que as relações entre o homem e o ambiente envolvem as próprias relações entre os homens, já que as imagens sobre a paisagem, o lugar e os fenômenos que os mesmos carregam que são produzidas no âmbito individual passam pelo escrutínio coletivo. Constantemente ressignificadas, estas imagens tornam-se ações práticas ou simbólicas que atuam sobre o ambiente, que se transforma e passa a transformar o homem. A participação social neste processo é um fato que atribui na trajeção de Augustin Berque (2017) um elemento a mais de complexidade dialética.

\section{O PÓS-MODERNISMO}

Há dúvidas sobre a origem exata do termo "pós-moderno" ou "pós-modernidade". A ideia de pósmodernidade emergiu nos primeiros anos após a Segunda Guerra Mundial, mas o seu uso seminal não corresponde exatamente ao uso holístico que se deu nos anos 1960 e 1970 (MINCA, 2009). Para além desta imprecisão temporal, dissertar sobre a pós-modernidade é desafiante. Afinal, o argumento da pós-modernidade lança um desafio às demais correntes filosóficas. Na sua forma mais pura, o pós-modernismo representa um ataque fundamental à filosofia contemporânea (DEAR, 1988 e 1994). Era de se esperar, portanto, que o pós-modernismo se tornasse alvo de um detalhado e plural escrutínio por parte de uma miríade de intelectuais. No âmbito da geografia, o pós-modernismo encontra resistência e até hostilidade por parte de outros que percebem sua chegada como uma ameaça à disciplina (MINCA, 2009). Notavelmente, autores identificados com o marxismo ${ }^{1}$ e com outras teorias sociais tem se dedicado a promover críticas contundentes. É importante acrescentar que poucas pessoas tem um claro senso sobre o que a pós-modernidade significa. Isto ocorre justamente pelas suas diversas manifestações, no campo da arquitetura, da literatura, da moda,

\footnotetext{
1 Os pressupostos pós-modernos tem sido descritos como anti-marxistas e tem sido adotados por alguns pesquisadores que se rotulam ou são rotulados como pós-marxistas (MINCA, 2009). Ao propor a desconstru ção do significado das materialidades coloca as premissas marxistas em uma situação de desconforto tal como também faz o idealismo da geografia humanista.
}
Caminhos de Geografia
Uberlândia-MG
v. 22, n. 82
ago./2021
p. 41-52
Página 43 
estética, dentre outras áreas. De acordo com Claudio Minca (2009), não existe um corpo singular e coerente acerca de uma teoria pós-moderna, o que ocorre justamente pela natureza dos pressupostos. Além da falta de consenso sobre o que é o "pós-moderno" nos conduz à incerteza sobre suas raízes históricas e seu desenvolvimento teórico ao longo do tempo (MINCA, 2009).

Os princípios sobre os quais repousavam as sociedades ocidentais perderam a sua credibilidade: é isto que leva muitos a dizer que vivemos a passagem para a pós-modernidade (CLAVAL, 1999). O pós-modernismo é basicamente uma revolta contra a racionalidade do modernismo (DEAR, 1994; CORREIA, 2008). Para Rogério Haesbaert (1997), o pós-modernismo colocou em xeque a própria legitimidade da razão como fundamento ou como única via para o conhecimento e a transformação do mundo. Portanto, é plausível considerar que o ponto de partida do pós-modernismo é a superação dos pilares que sustentam o modernismo. Muitos acreditam que estes pilares ainda estão de pé, apesar de estarem sujeitos a processos diferentes e mais intensos. Esta é uma argumentação contrária à pós-modernidade. Neste contexto de negação à pós-modernidade, é comum a referência à palavra hipermodernidade. Em um exemplo importante acerca desta desconfiança acerca do vigor dos pressupostos pós-modernos, Zygmunt Bauman (2001), em uma de suas obras mais icônicas, evita o uso da pós-modernidade ao preferir dissertar sobre a "liquidez da modernidade". Os que defendem a superação da modernidade geralmente tomam como referência as crises que adentram o campo das ideologias políticas, dos conceitos estéticos, dos raciocínios científicos, das co ncepções religiosas, das críticas filosóficas e culturais, enfim, de todo o espectro do conhecer (LEMOS, 1999).

Do ponto de vista teórico, a denominada pós-modernidade nega o universalismo e a generalização, que eram qualidades e procedimentos inerentes à modernidade. Há o questionamento quanto à existência de fronteiras rigorosas que dividem o saber em campos especializados (CORRÊA, 2000). Em oposição aos modernistas, há uma predominância do irracio nal que utiliza como ferramentas as formas, cores, imagens, metáforas e os sentidos, que são permanentemente reatualizados e reconstruídos. O modernismo busca uma verdade universal e repousar sobre a estabilidade do significado, usualmente por intermédio de um metadiscurso ou metanarrativa. O pós-modernismo assumiu a forma de uma revolta contra as rígidas convenções existentes sobre os métodos e linguagem (DEAR, 1988 e 1994; LEMOS, 1999; ANDERSON, 1999; EAGLETON, 1998; CORRÊA, 2000). Nas sociedades contemporâneas do "mundo pós-moderno", onde signos e símbolos são reciclados e até mesmo invertidos em diferentes contextos, não há estabilidade de significados, mas sim a liberdade da intertextualidade e interpretação (KONG, 1997). Para Jean-François Lyotard, a aurora da pós-modernidade é marcada pela ascensão de uma sociedade "que se baseia menos numa antropologia newtoniana (como o estruturalismo ou a teoria dos sistemas) e mais numa pragmática das partículas de linguagem" (LYOTARD, 2009, p.xvi). Por estas razõ es a abordagem pós-moderna é vista como portadora de um relativismo radical (MINCA, 2009).

Este quadro nos permite entender que a antítese do discurso da modernidade prega o anarquismo epistemológico aos modos de Paul Feyerabend (2011). É curioso pensar que o recuo diante da totalidade, a ênfase nos fragmentos da realidade e a desconstrução de uma ideia de verdade fazem com que se reafirme um fetiche pela epistemologia (PEDROSA, 2016). Esta é a conjuntura que explica o fato dos efeitos do discurso pós-modernista apresentarem-se desestabilizadores e anárquicos (DEAR,1988). Talvez seja esta a razão para o despertar de manifestos tão apaixonados contra os seus pressupostos. Apresentar o pós-modernismo a alguém é quase o mesmo que dizer que as bases que sustentam a sua crença não existem.

\section{O PÓS-MODERNISMO E O DEBATE SOCIAL}

No Brasil, a abertura para o debate da pós-modernidade na geografia foi ainda mais tardia comparativamente ao mundo anglófono e francófono. As obras de Soja (1993) e Harvey (2004) publicadas originalmente em 1989 - tiveram grande divulgação acadêmica, estando presente nas bibliotecas das principais universidades. Parte desta ampla divulgação explica-se justamente pelas suas formas de abordagem dotadas de forte apelo social, fazendo com que tivessem boa receptividade. O período de reabertura política no Brasil - ocorrida nos anos 1980 - esteve fortemente associado às leituras vistas como subversivas durante o regime militar, que substanciaram o desenvolvimento da geografia crítica brasileira. O ambiente político repressivo no Brasil explica certa imaturidade da geografia crítica brasileira frente às experiências europeias e americanas. Afinal, foi criada pela censura uma dificuldade de se estabelecer um franco diálogo com outros centros importantes da teoria crítica, como a França, o Reino Unido e os Estados Unidos. Pari Passu a este contexto, epistemologias que pregavam o rompimento com a ordem econômica global, motivadas 
pelo senso da existência de nações proletárias ${ }^{2}$ (LACOSTE, 1978), bem como as literaturas póscoloniais e decoloniais, reafirmaram a expressividade da geografia crítica. Acrescenta-se neste bojo a influência do alcance internacional da obra de Milton Santos, que acabou sendo um grande divulgador da geografia crítica no Brasil, alcançando projeção ainda maior após ser laureado com o prêmio Vautrin Lud no ano de 1994. Como os pressupostos pós-modernistas e os da geografia crítica antagonizam em muitos pontos, é compreensível que as críticas de abordagens marxistas e materialistas aos lampejos de discussões pós-modernas tenham se tornado tão ou mais abundantes do que as problematizações referentes às personificações do coletivo e outras materializações que passaram a ser alvo do escrutínio desconstrucionista.

Há, todavia, um paradoxo que envolve as teorias sociais e a pós-modernidade. Por um lado, a pósmodernidade desconstrói a materialidade das classes e propõe a intermediação de discursos, comprometendo as bases teóricas que substanciam os movimentos sociais, pelo menos em suas expressões quintessenciais. Por outro lado, certas manifestações sociais e expressões paisag ísticas pós-modernas são explicadas pelas teorias sociais. Este paradoxo somente é possível devido à pluralidade de sentidos que a pós-modernidade carrega. Exprime, também, relações destas formas de pensar no plano das ideias e das materializações, explicitando a oposição entre o idealismo e o materialismo. Preferimos nos referir ao fenômeno descrito como paradoxo à medida que consideramos que as duas manifestações aparentemente contraditórias das relações entre o pósmodernismo e as teorias sociais estão em um mesmo plano analítico, e não em planos diferentes e independentes. Afinal, acreditamos em um processo dialético que envolve as ideias e a materialidade.

As críticas à falta de sensibilidade social recaem sobre os pós-modernistas. Edward Relph salienta: "Não sei como é possível desenvolver uma visão e advogar por reformas sociais se nós não podemos ter clareza em como descrever o mundo" e ainda prega: "é desonesto desistir da visão de uma sociedade justa simplesmente porque o mundo pós-moderno é uma bagunça" (RELPH, 2001, p.150). Essas insatisfações e receios compõem críticas bem desenvolvidas ao pós-modernismo. Na base modernista marxista, o sujeito começa a ser pensado como nação, cultura, classe social, raça, ou seja, como um sujeito coletivo (LEMOS, 1999). O pós-modernismo rompe com esta ideia, ao pressupor que ninguém pode ser comparado a ninguém, abrindo espaço para o seguinte paradoxo: esta posição se trata de uma afirmação universalista e totalizante. A negação absoluta acerca sobre a identificação das pessoas com classes pode conduzir à situações que causam estranheza, como o fato de negar que Donald Trump seja capitalista (EAGLETON, 1998). Sobre este pres suposto pósmodernista, Terry Eagleton (1998) complementa que não há razão de assumir que, para as coisas pertencerem à mesma classe precisem apresentar exatamente as mesmas características essenciais. É justamente este argumento de Eagleton que vemos como problemático. Primeiramente, essa afirmação de Eagleton nos faz pensar como as pessoas de fato entendem as coisas inseridas na mesma classe. O fato de não haver razão de pensar que exista diferença no interior da classe social garante que as pessoas assim o entendam e ajam conforme sua premissa? No papel de proeminente intelectual, Terry Eagleton tem essa clareza e deve se policiar constantemente de modo a evitar a tentação totalizante. O pensamento estrutural notavelmente detém a hegemonia da observação à prima facie, como, por exemplo, nos faz opor o cru e o cozido (LÉVI-STRAUSS, 1964). Em segundo, acreditamos que no caso das pessoas, não devem ser as características essenciais que a definem como pertencente ao grupo "A" ou "B". O deslocamento dessa decisão deve ser feito para o âmbito do sujeito, independente das características. Mediante a natureza híbrida e permeável das culturas que o próprio EAGLETON (2011) reconhece, não parece ser assertivo estabelecer uma linha arbitrária para definir a quantidade de características compartilhadas que possa nos fazer decidir sobre o enquadramento de elementos em uma dada tipologia.

O problema é quando a teorização esbarra nas políticas públicas. Sem uma definição tangível sobre o que seja povo, nação, raça, dentre outras categorias, o discurso político de atendimento à subalternidade se esvazia. A mobilização política, por sua vez, também depende da ideia de consenso de grupo, tanto no que diz respeito às pautas reivindicatórias quanto na construção dos

\footnotetext{
${ }^{2}$ A ideia de nações proletárias expressa uma alusão à luta de classes marxista. No sentido desta expressão, assim como trabalhadores são explorados por patrões por meio da posse privada dos meios de pro dução, os países subdesenvolvidos são explorados pelos desenvolvidos por intermédio da divisão internacional do trabalho. Yves Lacoste (1978) afirma que a noção carregada pela expressão trata-se de uma falsificação do marxismo, pois conduz a considerar a população de cada Estado como um todo, e de fato como uma sociedade sem classes. Lacoste lembra ainda que "países subdesenvolvidos não são povoados somente por explorados; contam com exploradores poderosos" (LACOSTE, 1978, p.18).
}
Caminhos de Geografia
Uberlândia-MG
v. 22, n. 82
ago./2021
p. 41-52
Página 45 
simbolismos, dogmas e pressupostos que servem de amálgama das identidades em torno do grupo social. Terry Eagleton (1998) lamenta a colaboração do pós-modernismo para a desconstrução da ideia de uma história material, que poderia servir como narrativa apropriada à militância social e política. Acredita que o fato de não existir uma narrativa para amparar as vítimas das injustiças se constitui como algo a lamentar. Temos aqui outro desacordo teórico: o fato de múltiplas narrativas serem consideradas como interpretações da realidade intangível não significa que devamos dar o mesmo valor a todas as interpretações. Particularmente entramos também em desacordo com pós modernistas radicais. Nosso argumento nesta tentativa de mediação entre Terry Eagleton e a posição pós-modernista quintessencial é de que desconstruir o monopólio da verdade de qualquer narrativa não implica automaticamente na impossibilidade de hierarquizar as versões. Neste caso, a opressão e a subalternidade histórica se constituem como potenciais juízes, faltando-nos um mecanismo que liga estes árbitros metafóricos ao domínio das práticas. É justamente este vácuo que pode abrigar as manifestações intelectuais, a luta social e até mesmo a violência, em uma forma teórico-prática explorada por Hannah Arendt (2009). No campo teórico, todavia, sempre é importante lembrar que as narrativas são impressões espaço-temporais. Como a história continuará submetida à inexorabilidade temporal, a hierarquização das narrativas também precisa de revisões e ajustes constantes, por parte de quem as elabora e de quem as interpreta.

É possível encontrar, no entanto, engajamento frente a narrativas subalternas por parte de autores que versam a partir dos pressupostos da pós-modernidade. Nesse sentido, a preocupação com o "social" se mistura com outra obcecada empreitada pós-moderna: o fetiche pela subalternidade se explica não por uma militância pontual, mas como tentativa de encontrar nas narrativas de grupos minoritários e/ou oprimidos discursos que antagonizam com as metanarrativas tradicionais. Esta estratégia evidencia a polarização e permite que se reflita, por meio das posições antagônicas, a possibilidade de intermediação, desde que não se carregue a ingênua pretensão de dimensionar o "real".

Desconstruir posições parece ser, superficialmente e ao mesmo tempo, o apanágio e paradoxo da pós-modernidade. Afinal, a pós-modernidade também se constitui em uma posição teórica. Apesar de argumentos baseados em oposições tais como local-global ou socialista-capitalista não serem razoáveis para a dimensão pós-moderna (RELPH, 2001), afirmar que ninguém possa ser comparado essencialmente a ninguém equivale a uma afirmação universalista e totalizante (EAGLETON, 1998). Ironicamente, alguém que se identifica essencialmente com diversos pres supostos pós-modernistas pode se irritar em ser identificado como um pensador desta corrente. É importante observar que apesar destes aparentes paradoxos - se os pressupostos pós-modernistas se montam de tal forma que as suas próprias formulações são constantemente reformuladas, temos pelo menos dois resultados: a coerência teórica de um lado; e, de outro, uma ameaça à própria filosofia. Dear (1988) lembra que os pós-modernistas são acusados de promover o fim da filosofia. Apesar de considerar que não há um método claro para reconstruir o que os pós-modernistas desconstroem, Michael Dear acredita que a hermenêutica é um campo possível de racionalidade a partir da desconstrução (DEAR, 1988). A rejeição de uma metodologia hegemônica também tem duas faces: ao negar e desconstruir conceitos e significados é possível dizer que a pós-modernidade poderia estar, em sua forma mais pura, a serviço da neutralidade, que é um anseio da ciência moderna. Por outro lado, o permanente estado de desconstrução desmonta a tradição científica.

Leonard Guelke classifica o pós-estruturalismo como um movimento aliado ao pós-modernismo (GUELKE, 2003, p.98). Desenvolvida originalmente na França no período conhecido como virada linguística, a discussão pós-estrutural chegou à geografia no final dos anos 1980 e início dos anos 1990. O foco das interlocuções recaiu sobre a representação ${ }^{3}$, que se tornou chave para os geógrafos interessados em contribuir para o debate pós-estruturalista (WOODWARD; DIXON; JONES, 2009). A dialética entre matéria e ideias, que incluiu um processo de reconstrução contínua dos significados, também se manif esta no campo da intertextualidade, noção que integra um conjunto de pressupostos pós-estruturalistas. O intertexto é um campo relacional que serve à produção de novos contextos. Entre $o$ ato de ler e escrever, significados são desestabilizados e restabilizados

${ }^{3} \mathrm{~A}$ representação refere-se à mediação social que ocorre por intermédio do processo sempre presente de significação (WOODWARD; DIXON; JONES, 2009).

v. 22, n. 82

ago./2021

p. 41-52

Página 46 
novamente. Assim, os significados não podem ser entendidos como fixos. Ao contrário, estão semp re em processo, esperando a sua desconstrução (WOODWARD; DIXON; JONES, 2009). Dois campos de pesquisa são apontados como parte da agenda da geografia pós-estruturalista: o primeiro centrase na investigação da participação do contexto espacial na formação discursiva; o segundo campo foca na compreensão da representação do espaço propriamente dita (WOODWARD, DIXON E JONES, 2009).

A paisagem vista como um texto (ROWNTREE, 1986; 1988; COSGROVE; JACKSON, 1987; DUNCAN; DUNCAN, 1988) encaixa-se em alguns pressupostos pós-estruturalistas. Ao estabelecer a paisagem como intertexto, abre-se a possibilidade de considerar as formas integradas de pensamento. A intertextualidade muitas vezes é referida como a morte do autor. Nesta perspeciva, nenhum texto é plenamente autoral. Nesse sentido, o lugar de fala é questionado, o que interfere no valor que é atribuído ao discurso atribuído a classes específicas, bem como às narrativas subalternas. É por esta razão que autores marxistas escolhem como alguns dos seus inimigos preferenciais os pressupostos da pós-modernidade e a desconstrução pós-estruturalista que vem a reboque. Em uma espécie de conclusão do seu livro As ilusões do pós-modernismo, Terry Eagleton (1998) assim sacramenta sobre o pensamento pós-moderno:

No confronto com seus adversários políticos, a esquerda, hoje mais do que nunca, precisa de sólidos fundamentos éticos e mesmo antropológicos: é provável que nada menos que isso nos possa suprir dos recursos políticos de que necessitamos. E, nessa área, o pós-modernismo acaba sendo mais parte do problema do que da solução (EAGLETON, 1998, p. 130).

\section{O PÓS-MODERNISMO E OS ASPECTOS SOCIAIS URBANOS}

A dificuldade de analisar o real impacto da pós-modernidade na paisagem e no lugar reside justamente na multiplicidade de ef eitos que atuam sobre o espaço, tanto no arcabouço físico quanto na própria sociedade. Além disso, a pós-modernidade pode ser entendida como uma forma de ver o mundo, ou ainda, uma lente epistemológico-filosófica que posiciona o olhar em outra perspectiva. Do ponto de vista da paisagem e do lugar, a cidade parece ser o lócus principal do interesse da análise pós-moderna. Ambientes urbanos parecem ser mais sensíveis aos pressupostos que tentam explicar tanto a origem quanto as consequências da pós-modernidade.

Não é possível separar a logica da pós-modernidade de seus efeitos socioeconômicos sobre os ambientes urbanos (MINCA, 2009). Nesse sentido, o processo de fluidez econômica provocado pela acumulação flexível é indissociável à fetichização da heterotopia ${ }^{4}$ e da edificação de estruturaspastiche. Luís Mendes avalia o impacto das novas formas de organização produtiva sobre os espaços urbanos: a "transição para o novo regime de acumulação flexível do capital lê-se no território através do aumento da fragmentação urbana e de um mapeamento mais complexo das atividades e funções urbanas" (MENDES, 2011, p.477). O autor ainda completa sobre o conjunto urbano: "nas teorias da condição urbana pós-moderna, a cidade é hoje apreendida como um sistema complexo, irredutível à separação em funções elementares e em zonas estanques" (MENDES, 2011, p.477). Os tradicionais CBD [central business district] em uma condição urbana pós-moderna tendem a se desmanchar em fragmentos. A centralidade do urbano é substituída pela policentralidade. O impacto sobre o lugar é notório: ora sua centralidade observa perda relativa de posição, ora sua posição periférica torna-se mais central. É de se pesar, contudo, que cidades de tamanhos diferentes experimentem esse processo de forma distinta. Além disso, o próprio papel que as cidades desempenham nas redes urbanas regionais, nacionais e globais indicam a intensidade do fenômeno pós-moderno. Soja (1993) examinou a fragmentação de Los Angeles, manifesta não somente nas diferenças das nacionalidades como também nas distintas especializações e condições econômicas. A gentrificação em guetos urbanos surge como uma das manifestações do fenômeno de fragmentação social (MENDES, 2011).

\footnotetext{
${ }^{4}$ A multiplicação e o espessamento dos vetores dos fluxos de toda ordem, marca característica da ordem global, estimulou Foucault a analisar heterotopias. Vindo inicialmente do campo de estudo da anatomia, a palavra heterotopia aplicada ao espaço alude à presença de elementos que não são originais a um dado lugar e que por lá marcam presença. As heterotopias não surgiram recentemente. As grandes pedras que compõem o milenar Stonehenge foram trazidas de outros lugares. Por meio de sua dinâmica, criam novos tipos de lugares que tendem a se tornar, pelo menos durante um período, pontos de passagens obrigatórias para outros lugares (BARNES, 2004). As atuais geografias e suas paisagens não são menos indeterminadas, deslocadas e perplexas do que as epistemologias pós-modernas. A heterotopia parece ser uma forma precisa de ver o mundo e englobar a geografia arbitrária da justaposição de elementos (RELPH, 2001).
}

$\begin{array}{llllll}\text { Caminhos de Geografia } & \text { Uberlândia-MG } & \text { v. 22, n. 82 } & \text { ago./2021 } & \text { p.41-52 } & \text { Página } 47\end{array}$ 
Os modelos tradicionais de geografia urbana acerca da morfologia das cidades parecem não mais atender ao arranjo da cidade pós-moderna. As poderosas forças dos atores econômicos e as novas condições da vida social atuam sobre a cidade como uma onda avassaladora. Todavia, as rugosidades e os reverses salients, que se apresentam como nódoas de um tecido urbano extremamente desigual e pré-existente, absorvem e replicam de forma distinta esta onda. Esta é a razão para que o novo fenômeno que prostra a cidade frente aos seus desígnios, por um lado apresente-se imageticamente como uma força coesa e homogênea, e, por outro, seja a razão primordial para a ampliação das desigualdades intraurbanas.

Os efeitos sociais são igualmente notáveis: a multiplicidade de gêneros, as distintas musicalidades, modelos de família e outras tipologias que pulverizam a ordem social fazem que a cidade pós moderna seja o lugar preferencial da morte do vernacular. O processo de transferência de bits geográficos e trocas culturais não são exatamente novos, mas nos tempos pré-modernos os processos eram suficientemente lentos e ineficientes que quase sempre eram adaptados às circunstâncias locais (RELPH, 2001).

As paisagens vernaculares têm sido colocadas em xeque. Argumentar sobre a instabilidade dos significados e expulsar toda e qualquer autenticidade da paisagem virou um clichê pós-moderno ( $\mathrm{CROUCH}, 1991)$. A hibridez arquitetônica, as heterotopias, a fragmentação do espaço urbano e a reunião de experiências identitárias extremamente marcadas pelo deslocamento espacial são múltiplos ef eitos da pós-modernidade percebidas na paisagem e no lugar, no âmbito trajetivo entre a materialidade e as ideias.

\section{CONSIDERAÇÕES FINAIS}

Consideramos que neste ponto do texto temos a possibilidade de discutir a questão que envolve a pós-modernidade e o pensamento social. Seriam complementares ou representariam um antagonismo?

Não temos a firmeza de Terry Eagleton (1998) de afirmar que a pós-modernidade é mais um problema do que solução para o debate sociopolítico. A discussão que envolve o pensamento pós moderno e as teorias sociais evidencia o embate entre teoria e militância. É difícil encontrar argumentos que desconsiderem a relevância das injustiças sociais fruto das relações de poder historicamente construídas. Todavia, o pensamento pós-moderno parece criar dificuldades práticas para a militância. O desajuste entre teoria pós-moderna e aplicações práticas direcionadas ao pensamento social parece se explicar por uma imaturidade do campo de pensamento. Como já dissemos, parece existir uma lacuna entre a percepção da injustiça social como fenômeno e a forma de contribuição do pós-modernismo para tratar a questão. Não é de se estranhar que o pósmodernismo seja acusado de academicismo vazio. No campo da discussão teórica há robustez na reflexão: a desconstrução do lugar de fala, dos significados e o questionamento sobre as classes entendidas como corpos homogêneos de pensamento, são problematizações muito bem amparadas e suportadas pela teoria. Talvez o apreço pela diversidade, instabilidade e excepcionalidade bem marcantes na teoria pós-moderna sejam a chave para uma nova e abrangente perspectiva sobre a tolerância. Se as teorias econômicas e sociais foram incapazes de frear a ampliação das desigualdades econômicas, talvez encontremos justamente na ideia de uma humanidade plural e livre de classes reificadas a base para uma construção lenta e dolorosa de uma nova ordem.

Dentro deste embate envolvendo a pós-modernidade, o pós-estruturalismo e a reflexão social, Oakes (1997) considera que o revigoramento do conceito de lugar realizado pelos pressupostos destas correntes criou um drama para as políticas culturais e sociais. Esta afirmação parte da perspectiva de que as posições destas correntes implicam na criação da resistência quanto aos ef eitos objetivos do capitalismo, patriarcalismo, colonialismo e nacionalismos, e, acrescentando por nossa iniciativa, uma miríade de outros "ismos". Esta posição não é o mesmo que negar a atuação destas doutrinas sobre o comportamento humano, mas acreditar que é impossível isolar os seus efeitos sobre uma dada coletividade ou individualidade, já que os "ismos" atuam conjuntamente. Esta referida atuação conjunta das doutrinas nos faz entender que a contradição do pensamento e comportamento humano não é uma exceção. Fragmentos doutrinários congruem, antagonizam e se complementam caleidoscopicamente. O lugar é sem dúvida um terreno de lutas. Estas lutas, todavia, não podem ser totalmente encaixadas em termos de uma resistência às hegemonias históricas e espaciais. Fazendo uma contraposição entre pós-modernidade e modernidade, Timothy Oakes salienta: "O lugar, eu argumento, representa a geografia da modernidade e toda a sua riqueza contraditória" (OAKES, 
1997, p.520). Com esta frase, o autor refere-se a pós-modernidade como conjunto retalhado de discursos modernos.

Há uma má interpretação de que a consideração de múltiplas narrativas e a quebra do monopólio da verdade histórica nos conduzam a uma posição de colocar todas as tentativas de intermediação da realidade em um mesmo plano valorativo. Este é um tema muito sensível para a contemporaneidade. Com a democratização do acesso à internet, a disponibilidade e ritmo de atualização da informação aumentaram exponencialmente. A externalidade diretamente ligada a este processo é a disseminação das fake news, que interferem em vários âmbitos da vida cotidiana. Sob as escusas de que toda narrativa é válida, há quem defenda que o planeta Terra é um plano. Ao mesmo tempo, teorias conspiratórias das razoáveis às mais esdrúxulas se oferecem. Acreditamos que surge no vácuo da demolição das metanarrativas idealizada pelo pós-modernismo a possibilidade de intermediação de pontos de vista. É justamente a riqueza de nossa experiência frente ao fenômeno interpretado pela nossa intermediação que promove inapelavelmente a hierarquização de narrativas. Como o processo de intermediação não se esgota devido à essência inexorável da totalidade, estamos fadados a confrontar, descontruir e ressignificar o sentido daquilo que, em um nível pesso al, apresenta-se a nós como o domínio do real. Por esta razão, posições fortemente enviesadas por doutrinas e fracamente intermediadas no campo discursivo acabam saltando aos olhos de um interlocutor que se encontra imerso em um processo mais diversificado de intermediação.

Acreditamos, diante de nossas considerações, que o pós-modernismo e o pensamento social se complementam no antagonismo. Não é esta uma reposta elusiva vazia: dada a polissemia do pós modernismo, temos na deconstrução de narrativas, de classes e conceitos, uma dificuldade discursiva para o pensamento social; todavia, as críticas da pós-modernidade frente aos efeitos urbanos da fragmentação espacial mostram-se muito poderosas, como nos mostrou Edward Soja (1993). É importante destacar que o desconstrucionismo que quebra o monopólio dos métodos cientificos modernos, abre uma oportunidade para que a teoria social não se veja mais obrigada à verificação empírica. Fica claro nesta perspectiva de que as questões associadas à busca pela legitimação científica não atormenta mais as humanidades no contexto do zeitgeist pós-modernista.

Apoiamos a tese de Michael Dear (1988) que destacando o fato que a geografia chegou tardiamente ao debate pós-moderno, acredita que a disciplina precisa aprender como lidar com os pressup ostos da referida corrente, sob o risco de perder o seu protagonismo como uma importante área do debate das humanidades. Para tanto, o autor parte da crença de que tais pressupostos já marcam presença na contemporaneidade, possuindo vigor explicativo para as relações espaciais, campo de preocupação geográfica.

\section{REFERÊNCIAS}

ANDERSON, Perry. As origens da pós-modernidade. Rio de Janeiro: Jorge Zahar, 1998. 165p.

ARENDT, Hannah. Sobre a violência. Rio de Janeiro: Civilização Brasileira, 2009. 167p.

BARNES, Trevor. Placing ideas: genius loci, heterotopia and geography's quantitative revolution. Progress in Human Geography, v.28, n.5, p.565-595, 2004. https://doi.org/10.1191/0309132504ph506oa

BAUMAN, Zygmunt. Modernidade líquida. Rio de Janeiro: Jorge Zahar, 2001. 278p.

BERQUE, Augustin. Geogramas, por uma ontologia dos fatos geográficos. Geograficidade, v.2, n.1, verão, p.4-12, 2012. https://doi.org/10.22409/geograficidade2012.21.a12816

BERQUE, Augustin. A cosmofania das realidades geográficas. Geograficidade, v.7, n.2, p.4-16, inverno, 2017. https://doi.org/10.22409/geograficidade2017.72.a12977

CABRAL, Luiz Otávio. A paisagem enquanto fenômeno vivido. Geosul, v.15, n.30, p.34-45, jul/dez, 2000.

CAPEL, Horácio. Neopositivismo e Geografia Quantitativa. (in): Capel, Horacio. Ruptura e continuidade no pensamento geográfico. Maringá: EDUEM, 2013. 190p. p.21-39.

CLAVAL, Paul. O território na transição da pós-modernidade. Geographia, v.1, n.2, p.7-26, 1999. https://doi.org/10.22409/GEOgraphia1999.12.a13349 
CORRÊA, Margarida Maria da Silva. A pós-modernidade e as atuais orientações da geografia humana. Boletim Goiano de Geografia, v.20, n.1-2, p.43-76, jan/dez, 2000.

https://doi.org/10.5216/bgg.v20i1.4228

CORRÊA, Roberto Lobato; ROSENDAHL, Zeny. Sobre Carl Sauer: uma introdução. (in) CORRÊA, Roberto Lobato; ROSENDAHL, Zeny (Orgs.) Sobre Carl Sauer. Rio de Janeiro: Eduerj, 2011.

CORREIA, Marcos Antonio. A geografia humanista no III milênio: uma nova perspectiva. Luminaria, v.1, n.9, p.140-148, 2008.

COSGROVE, Denis. Place, landscape, and the dialetics of cultural geograp hy. Canadian Geographer, v.XXII, n. 1, p.66-72, 1978. https://doi.org/10.1111/j.1541-0064.1978.tb01218.x

COSGROVE, Denis E. Towards a radical cultural geography: problems of theory. Antipode, Vol. 5, Issue I, p.1-11, 1983. https://doi.org/10.1111/j.1467-8330.1983.tb00318.x

COSGROVE, Denis. Ideas and culture: a response to Mitchell. Transactions of the Institute of British Geographers, v.21, p.574-575, 1996. https://doi.org/10.2307/622598

COSGROVE, Denis; JACKSON, Peter. New Directions in Cultural Geography. Area, vol.19, n.2, jun, p.95-101, 1987.

CRESSWELL, Tim. New cultural geography - an unfinished project? Cultural geographies, v.17, n.2, p.169-174, 2010. https://doi.org/10.1177/14744744010363845

$\mathrm{CROUCH}$, David. The authentic, the everyday and the postmodern in landscape research: a note. Landscape Research, v.16, n.2, p.8-18, 1991. https://doi.org/10.1080/01426399108706340

DEAR, Michael. The Postmodern Challenge: Reconstructing Human Geography. Transactions of British Geographers, new series, v.13, n.3, p.262-274, 1988. https://doi.org/10.2307/622990

DEAR, Michael. Postmodern Human Geography: A Preliminary Assessment. Erdkunde, v.48, n.1, p.2-13, march, 1994. https://doi.org/10.3112/erdkunde.1994.01.01

DUNCAN, James; DUNCAN, Nancy. (Re)reading the landscape. Environmental and Planning D.

Society and Space, v.6, p.117-126, 1988. https://doi.org/10.1068/d060117

DUNCAN, James; DUNCAN, Nancy. Reconceptualizing the Idea of Culture in Geography: A Reply to Don Mitchell. Transactions of the Institute of British Geographers. New Series, v.21, n.3, p.576579, 1996. https://doi.org/10.2307/622599

EAGLETON, Terry. As ilusões do pós-modernismo. Rio de Janeiro: Jorge Zahar, 1998. 141p.

EAGLETON, Terry. A ideia de Cultura. São Paulo: Editora Unesp, 2011. 204p.

FEYERABEND, Paul. Contra o Método. São Paulo: Editora Unesp, 2011. 372p.

GOLD, John R.; GOODEY, Brian. Behavioural and perceptual geography. Progress in Human Geography, v.7, p.578-586, 1983. https://doi.org/10.1177/030913258300700406

GREGSON, Nicky. Beyond boundaries: the shifting sands of social geography. Progress in Human Geography, v.16, n.3, p.387-392, 1992. https://doi.org/10.1177/030913259201600305

GUELKE, Leonard. Nietzsche and postmodernism in geography: An idealist critique. Philosophy \& Geography, v.6, n.1, p.97-116, 2003. https://doi.org/10.1080/1090377032000063342

HAESBAERT, Rogério. Questões sobre a (pós-) modernidade. Geouerj, n.2, p.7-22, 1997.

HARTSHORNE, Richard. Propósitos e natureza da geografia. São Paulo: Edusp, 1978. 203p.

HARVEY, David. Explanation in Geography. Bristol: Edward Arnold, 1986. 521p.

HARVEY, David. Condição Pós-Moderna. São Paulo: Edições Loyola, 2004. 349p.

INGOLD, Tim. The temporality of the landscape. World Archaelogy, v.25, n.2, p.152-174, 1993. https://doi.org/10.1080/00438243.1993.9980235

JACKSON, Peter. The idea of culture: a response to Don Mitchell. Transactions of the Institute of British Geographers, v.21, p.572-573, 1996. https://doi.org/10.2307/622597

JOHNSTON, R. J. Geografia e Geógrafos. São Paulo: Difel, 1986. 359p.

\begin{tabular}{|c|c|}
\hline$C$ & Uberlândia-MG \\
\hline
\end{tabular}


KONG, Lily L. L. A "new" cultural geography? Debates about invention and reinvention. Scottish Geographical Magazine, v.113, n.3, p.177-185, 1997. https://doi.org/10.1080/00369229718737011 LACOSTE, Yves. Geografia do Subdesenvolvimento. São Paulo e Rio de Janeiro: Difel, 1978. 265p.

LACOSTE, Yves. A geografia - isso serve, antes de tudo, para fazer a guerra. Campinas: Papirus, 2005. 263p.

LEITE, Adriana Filgueira. O lugar: Duas Acepções Geográficas. Anuário do Instituto de Geociências-UFRJ, v.21, p.9-20, 1998. https://doi.org/10.11137/1998 0 9-20

LEMOS, Amalia Inés Geraiges. Geografia da modernidade e geografia da pós-modernidade. Geousp, v.3, n.1, p.27-39, 1999.

LÉVI-STRAUSS, Claude. Le cru et le cruit. Paris: Plon, 1967. 402p.

LEY, David. Cultural/humanistic geography. Progress in Human Geography, v.5, p.249-257, 1981. https://doi.org/10.1177/030913258100500205

LYOTARD, Jean-François. A condição pós-moderna. Rio de Janeiro: José Olympio, 2009. 131p.

MENDES, Luís. Cidade pós-moderna, gentrificação e a produção social do espaço fragmentado.

Cadernos metrópole, v.13, n.26, p.473-495, jul/dez, 2011.

MIKESELL, Marvin W. Tradition and innovation in cultural geography. Annals of the Association of American Geographers, v.68, n.1, p.1-16, march, 1978. https://doi.org/10.1111/j.14678306.1978.tb01176.x

MINCA, Claudio. Postmodernism/Postmodern Geography. (in) KITCHIN, Rob, THRIFT, Nigel. Encyclopedia of Human Geography. Elsevier, Amsterdam, 2009. https://doi.org/10.1016/B978008044910-4.00725-2

MITCHELL, Don. There's No Such Thing as Culture: Towards a Reconceptualization of the Idea of Culture in Geography. Transactions of the Institute of British Geographers. New Series, v.20, n.1, p.102-116, 1995. https://doi.org/10.2307/622727

MITCHELL, Don. Explanation in Cultural Geography: A Reply to Cosgrove, Jackson and the Duncans. Transactions of the Institute of British Geographers, v.21, n.3, p.580-582, 1996. https://doi.org/10.2307/622600

NAME, Leo. O conceito de paisagem na geografia e sua relação com o conceito de cultura. Geotextos, v.6, n.2, dez., p.163-186, 2010. https://doi.org/10.9771/1984-5537geo.v6i2.4835

OAKES, Timothy. Place and the Paradox of Modernity. Annals of the Association of American Geographers, v.87, n.3, p.509-531, 1997. https://doi.org/10.1111/1467-8306.00066

PEDROSA, Breno Viotto. O império da representação: a virada cultural e a geografia. Espaço e Cultura, UERJ, n.39, jan./jun, p.31-58, 2016. https://doi.org/10.12957/espacoecultura.2016.31750

POCOCK, Douglas C. D. The paradox of human geography. Area, v.15, n.4, p.355-358, 1983.

RELPH, Edward. The critical description of confused geographies (in): ADAMS, Paul C.;

HOELSCHER, Steven; TILL, Karen E. Textures of Place. Minneapolis and London: Minnesota University Press, 2001. 443p. p.176-191.

ROWNTREE, Lester. Cultural/humanistic geography. Progress in Human Geography, v.10, n.4, p.580-586, 1986. https://doi.org/10.1177/030913258601000408

ROWNTREE, Lester. Orthodoxy and new directions: cultural/humanistic geography. Progress in Human Geography, v.12, n.4, p.575-586, 1988. https://doi.org/10.1177/030913258801200409

SACK, Robert David. Geography, Geometry and Explanation. Annals of the Association of American Geographers, v.62, n.1, p.61-78, March, 1972. https://doi.org/10.1111/j.14678306.1972.tb00844.x

SACK, Robert David. Chorology and Spatial Analysis. Annals of the Association of American Geographers, v.64, n.3, p.439-452, September, 1974. https://doi.org/10.1111/j.14678306.1974.tb00992.x

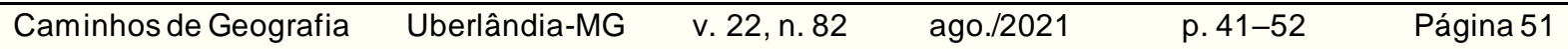


SAUER, Carl. A morfologia da paisagem. (in): OAKES, Timothy S; PRICE, Patricia L (eds). The Cultural Geography Reader. New York: Routledge, 2008.

SCHAEFER, Fred K. Excepcionalism in Geography: A methodological examination. Annals of the association of American geographers. Vol.43, number 3, p.226-249, 1953.

https://doi.org/10.1080/00045605309352114

SCOTT, Heidi. Cultural Turns (in): DUNCAN, James S.; JOHNSON, Nuala C.; SCHEIN, Richard H. A companion to cultural geography. Malden: Blackwell Publishing Itd, 2004.

SOJA, Edward W. Geografias Pós-Modernas. Rio de Janeiro: Jorge Zahar, 1993. 324p.

SMITH, Neil. Geography, Science and post-positivist modes of explanation. Progress in Human Geography, v.3, i.3, p.356-383, 1979. https://doi.org/10.1177/030913257900300302

VALENTINE, Gill. Whatever happened to the social? Reflections on the "cultural turn" in British Human Geography. Norwegian Journal of Geography, v.55, p.166-172, 2001.

https://doi.org/10.1080/002919501753129925

WALTON, Judy R. How Real(ist) can you get? Professional Geographer, v.47, i.1, p.61-65, 1995. https://doi.org/10.1111/j.0033-0124.1995.00061.x

WOODWARD, K; DIXON, D. P; JONES, J. P. Poststructuralism/Poststructuralist Geographies. (in) KITCHIN R; THRIFT N. (eds). International Encyclopedia of Human Geography. Oxford: Elsevier, v.8, p.396-407, 2009. 8250p.p.396-407. https://doi.org/10.1016/B978-008044910-4.00727-6

Recebido em:25/06/2020

Aceito para publicação em: 13/08/2020 